\title{
A Computational Approach to Assessing Rhetorical Effectiveness: Agentic Framing of Climate Change in the Congressional Record, $1994-2016$
}

\author{
Zoltan P. Majdik, Ph.D. \\ North Dakota State University \\ Department of Communication
}

\begin{abstract}
The goal of this paper is to consider rhetorical effects as the propagation of rhetorical expressions across large sets of texts, measured by the extent to which rhetorical expressions, structures, or practices become replicated in texts and sites of rhetorical in(ter)vention. The paper draws on lines of scholarship in the digital humanities and computational rhetoric - primarily, sequential structuring of semantic contexts, semantic parsing of unstructured text, and diachronic tracking of textual expressions - to extend their conceptual and methodological insights into a computational framework for assessing rhetorical effectiveness. It offers a test case for this concept through an analysis of how Congress has framed human agency toward addressing climate change.
\end{abstract}

\section{Keywords}

Climate change; Digital humanities; Computational rhetoric; Rhetorical effects 


\section{Publication Info}

Pre-print disclaimer. This PDF is a pre-print of a manuscript that has been accepted for publication. It looks different from the Version of Record. To access the most updated version, and to cite from this document, refer to:

Majdik, Zoltan P. A Computational Approach to Assessing Rhetorical Effectiveness: Agentic Framing of Climate Change in the Congressional Record, 1994-2016. Technical Communication Quarterly XX, no. X (2019): p-pp. https://doi.org/10.1080/10572252.2019.1601774. 


\section{Introduction}

The goal of this paper is to conceptualize a framework for assessing the success of rhetorical practices and expressions within a large discursive space. The paper argues that computationally tracking how distinct rhetorical expressions increase or decrease in prevalence over time provides a framework for engaging questions about rhetorical effectiveness; it allows for mapping the "life," or circulation, of rhetorical expressions as textual imprints that become replicated across general or specialized discourses relative to and against other rhetorical expressions. The paper so takes as its starting point theories of rhetoric that understand rhetoric from cultural (Farrell, 1993) and communication from systemic (Luhmann, 1992) instead of primarily psychological perspectives. As a test case for this concept, the paper shows how two distinct agency frames in Congressional deliberations on climate change shift in prevalence over time, arguing that climate change frames foregrounding combative action have become more effective as Democratic control of Congress ended and transitioned into split- and Republican-controlled Congresses over the last few years.

Technical communication scholars have long been interested in climate change, often drawing from and contributing to multiple disciplines in their work (for an overview, see Cagle \& Tillery, 2015). Whether implicit or explicit, much of this work hinges on questions of effect: the effectiveness of public communication on policy deliberation, for example (Spoel et al, 2008), or of visuals on public deliberation (Walsh, 2015). Such questions of effect hinge on the need to make communicative practices useable in technical spaces: on the effective ability of rhetoric of science, for example, to actually act (Herndl \& Cutlip, 2013), or on the ability to effectively communicate risk against barriers like diachronic distance of a hazard, complexity of the problem, and uncertainty of solutions (see, e.g., Slovic, 1986; or Schäfer \& Schlichting, 2014, for an overview).

This paper argues that for these reasons, technical communication scholarship can benefit from considering the question of "effect" not only causally (what types of communication can effectively do something) but, as described above, also systemically (what types of communication are effectively doing something). The latter paradigm represents communication as "an emergent reality" (Luhmann, $1992)^{1}$, as the (dynamically changing) state of norms in a rhetorical system. In so doing, it offers two possibilities. One is resources for technical communicators. With reference to Herndl \& Cutlip (2013), it offers both a curiosity-orientation and a mission-orientation; its representation of the (emergent) state of rhetorical norms also constitutes the resources for communicative practice, for intervening into that space. Mapping and visualizing which communicative approaches gain and lose acceptance over time in a technical, discursive system can help in doing the work of communication. ${ }^{2}$ In this sense, assessing rhetorical effectiveness

\footnotetext{
${ }^{1}$ For similar systems perspectives on scientific rhetorical practices, see Derkatch, 2018; Keränen, 2010.

${ }^{2}$ This systems-view of communication is why I take prevalence rather than salience as
} 
across an entire discursive system treats rhetoric as techne, as a productive craft (Miller, 1989).

But as Miller suggests, technical communication can, and should, consider rhetoric differently as well: not just as a tool toward the production of communicative "goods," but also as praxis, a kind of conduct, in which it provides a "locus for questioning, for criticism, for distinguishing good practice from bad" (p. 69). Mapping the work of rhetoric - its effects - maps a rhetorical culture. It makes intelligible motives and audiences and norms of reciprocity (Farrell, 1993); it makes visible presuppositions for acceptance and rejection of utterances, and hence of communicative risk (Luhmann, 1992; see also footnote 1), which serve as bases for questioning and criticism of actual communicative practices.

The paper offers a test case for this argument that draws methodologically on scholarship in computational rhetoric and digital humanities, and scales it to assess rhetorical effects as the propagation of rhetorical expressions across large textual corpora, through identification of central semantic features, semantic parsing of unstructured text, and diachronic tracking of textual expressions. The test case focuses on how climate change is rhetorically positioned in Congressional deliberations over the last 22 years, by identifying the predominant agentic frames through which Congressional discourse has framed human capability relative to climate change: a passive-agentic frame (focused on continued study of climate change) and an active-agentic one (focused on more immediate intervention in climate change. The analysis of these rhetorical frames centers on their effectiveness: which rhetorical frames are most frequently represented across a textual corpus (and so statically represent the rhetorical norms of the discursive system), and which frames gain and wane in prevalence over time (and so reveal the emergent norms of a discursive, rhetorical system).

a measure of rhetorical effectiveness, and measures of rhetorical effectiveness as a resource for communicative practice. To follow Luhmann, prevalence of rhetorical expressions creates "redundancy," a "memory that can be called on my many persons." These redundancies calcify into (communicative) institutions that can "guarantee acceptability" (i.e., reduce the risk of rejection) of utterances made by individual communicators; they identify positions "of connection for the next communication that can now either build on an already attained consensus or seek dissent." Hence, although a novel or inventive or particular act of communication can, of course, be effective in intervening in a life-world if its content and structure is particularly salient to the moment, from a broader use-perspective, those acts of communication ca not be abstracted into a resource for others to use in other moments, nor can they be leveraged as points of critique for general practices of communication. 


\section{Background: Tracking Rhetorical Frames and Conceptualizing their Effectiveness in Large Corpora}

\section{Toward rhetorical effects}

The paper's argument on what constitutes rhetorical effectiveness requires perspectives on rhetoric that locate effectiveness in textual more than behavioral registers. Aristotle may be seen as a precursor: his claim that "[rhetoric's] function is not so much to persuade, as to find out in each case the existing means of persuasion" reflects a systems-view of rhetoric's effects. If the goal of rhetoric is judgment in conditions of uncertainty, then what matters for an effective rhetorical practice is the critical awareness of the means and norms of persuasion that impinge on a deliberative situation, not to map specific rhetorical expressions to specific audience reactions. Hence, when Wichelns (1925) stated that rhetorical analysis is "not concerned with permanence, nor yet with beauty. It is concerned with effect. It regards a speech as a communication to a specific audience" [my emphasis], many were quick to (re-)locate that effect in textuality rather than psychology. As Wayland Parrish (1954) argued, the quality of rhetoric should not be measured against a specific audience: "We admire Burke's great addresses, not because they were well adapted to the boozy country squires who sometimes sat in Parliament, but because they were designed for a better audience."

Others, too, sought to locate effectiveness more distinctly in the textual reach of rhetorical expressions and practices. Wrage (1947) suggests an "idea centered" model of rhetoric that emphasizes a "vast quantity of documentary sources" in which ideas modified by rhetoric exist, and the importance of thinking about linkages between ideas and between many speeches as measures for observing "the reflections of prevailing social ideas and attitudes" (pp. 454, 456). Black (1970), whose Rhetorical Methods already had sought to break with Wichelns' focus on immediate effects, argues that although evidence for (in his case, ideological) effects of a discourse is most evident in the discourse's substantive claims, the "more likely evidence available will be the form of stylistic tokens" (p. 112). Rand (2008), similarly, argues that "By 'effectivity' I mean to convey the ways in which any rhetorical action is taken up [... it] refers not to the degree to which the effects of a polemic match the polemicist's intentions, but to the ways in which it is put to use or taken up by others in a variety of different and unforeseen fashions" (p. 309). Browne (2001), too, notes that effectiveness should be measured through "units of discourse" (p. 333), while Heidt (2012) argues that making "claims relating to audience and rhetorical effect" requires tracing "the atomization, distribution, and recirculation of the elements of presidential address" (p. 629), and for Greene (1998), effect comes from "linking a fragment to a structure of signification (p. 35). 
Importantly, none of these theories of rhetorical effect locate effect in a behavioral idea, in which rhetorical structures would be argued to act as stimuli that affect behavioral changes in audiences. Rather, effect is the textual "imprint" (see also: Campbell \& Jamieson, 1978) of a rhetorical practice or expression or form, the extent to which it becomes replicated in other texts and other sites of rhetorical in(ter)vention, aligned both in idea and in its value as resource for communicative practice with the kind of communicative systems paradigm discussed by Luhmann. The concept of rhetorical effectiveness proposed in this paper proceeds from this understanding of effect. ${ }^{3}$ But doing so raises questions of scope. If technical communication is invested in not only techne but also praxis (Miller, 1989), then for analysis of rhetorical effects to serve as a resource for technical communicators requires those effects to be understood in and across the totality of their discursive system (see footnote 1; Luhmann, 1992). The paper, then, concerns itself with how rhetorical effects, as discursive "tokens," "imprints," or units with "use-value," propagate ${ }^{4}$ across large numbers of texts, and grow or wane in impact, not so much on actual audiences, but in how readily they make available distinct communicative ways of associating with or departing from the norms of an extant discursive system. This approach poses a methodological challenge that will be addressed in the next section.

\section{Tracking rhetorical effects}

The paper's test case for conceptualizing rhetorical effectiveness is interested in agency frames (one of the five traits of frames suggested by Entman, 1991) in Congressional discourse, and follows Nerlich \& Koteyko's (2009) concept of "lexical framing" in treating words and word compounds as meaningful framing devices. ${ }^{5}$ Framing of scientific issues in policy discourses can have a number of impactful downstream effects on how science gets produced and used (see, e.g., Vink, Boezeman, Dewulf, \& Termeer, 2013; Park, Liu, \& Vedlitz, 2014). Yet, extended discussion of climate change in Congress began comparably recently. The Congressional Record - the daily publication of the proceedings of both houses of Congress - shows that discussion of climate change spiked in 2007,

\footnotetext{
${ }^{3}$ For a more complete discussion of effects in rhetoric, see Kiewe and Houck's (2015) introduction to The effects of rhetoric and the rhetoric of effects.

${ }^{4}$ See also Campbell \& Jamieson (1978) on the "recurrence" of rhetorical forms, as an index of "human action," the "influence of conventions on the responses of rhetors," of "rhetorical options or commonplaces," as "insight into the human condition," and as making accessible (rhetorical) "affinities and traditions across time (pp 26, 27); or Greene (1998) in a critical/materialist turn, in which "rhetoric distributes different elements on a terrain of a governing apparatus," yielding "a form of cartography" (pp. 38, 39).

${ }^{5}$ The relative linguistic/syntactic simplicity of lexical framing serves to more clearly illustrate the computational dimension of the test case, because such frames have limited semantic and little syntactic variation (see subsequent section for how such variation is methodologically captured). My hope is that subsequent research can build on it to encode more complex rhetorical structures for tracking/mapping, whether they be frames with more complex structure (like thematic frames, or Burkean acceptance/rejection frames), tropes, figures, narrative structures, genres, etc.
} 
when mentions of "climate change" or "global warming" rose from the mid-100s and low 1000s in previous years to over 4000 (see Table 1, below, for a more detailed description of the corpus).

Given the scope of Congressional deliberative texts, any analysis of its rhetorical features that limits itself to a small sampling of deliberative exchanges will offer at best a snapshot into how U.S. policy discourse has framed agentic possibilities about climate change. Between 1994 and 2016, the Congressional Record includes 5679 documents that include discussion of climate change, and over 30,000 mentions of the term 'climate change' or 'global warming' 6 within those exchanges. Hence, to offer more than a snapshot of how effective specific frames for climate change are compared to others requires a quantitative component, one that should accomplish three objectives. It should include affordances for exploratory, inductive "reading" across a large textual corpus to help identify salient rhetorical expressions and semantic contexts. It should be able to identify and tag these expressions at the scope of a phrase, sentence, or paragraph, as rhetorical practices tend to operate within and across these syntactic units. And it needs to show changes over time; because a rhetorical culture is dynamic (frames and other rhetorical devices react to external drivers and internal rhetorical forces), questions about effects ask how rhetorical framing changes over time more than what the rhetorical frames are.

The computational parsing and tagging of semantic elements of language represents a challenge addressed in computational linguistics and rhetoric (for an overview of work in the latter, see Ridolfo \& Hart-Davidson, 2015). Some approaches in computational linguistics start with syntactic considerations (see, e.g., Mann \& Thompson, 1988); others access semantic contexts by weighting words based (inversely) on prevalence in a corpus, and deriving meaning through vector representations (see, e.g., Gabrilovich \& Markovitch, 2007).

Of interest to this paper's goal are computational tools designed to parse and tag distinctly rhetorical expressions. Many are focused on identifying tropes, most commonly metaphors (David, Lakoff, \& Stickles, 2016; Dodge, 2016; Jisup Hong, 2016; Weber Russell, 2008). Others have made advances in computationally identifying figures (Gawryjolek, Dimarco, \& Harris, 2009; Kelly, Abbott, Harris, DiMarco, \& Cheriton, 2010). Graham, Kim, DeVasto, \& Keith (2015) use a method they call "statistical genre analysis" to parse genre differences across large textual corpora (see also Kaufer \& Hariman, 2008). And Hart (2001)'s DICTION project is designed to identify the tone of messages computationally based on a number of features and sub-features. Hoffman \& Waisanen (2015) have generated a summary of these tools for computational rhetoric.

One challenge for rhetorical scholarship using computer-assisted semantic tagging and analysis in larger textual corpora is that such corpora frequently are comprised of documents from a wide range of domain-specific discourses, not

\footnotetext{
${ }^{6}$ The term "global warming" is included to capture documents, particularly those in the early years of the dataset, that still used this term over "climate change."
} 
all of which are relevant to a research question. Tagging semantic features indiscriminately across a corpus, without narrowing which of its salient rhetorical features through initial, discovery-oriented reading of the corpus, can in large corpora yield results of questionable validity and usefulness. Nerlich, Forsyth, \& Clarke (2012)'s analysis of climate media discourse demonstrates one option for expression-level inductive discovery of salient semantic contexts across large textual corpora. The researchers develop a generic n-gram based model of inter-term intervals to identify (and contrast) semantically interesting units in a large corpus. As discussed later, this paper uses a version of n-gram collocatesbigrams - for an initial inductive discovery of salient semantic features in its textual corpus.

Another challenge for assessing the effectiveness of rhetorical practices is the ability to diachronically track and compare the prevalence of rhetorical expressions relative to each other across textual corpora that span time frames of multiple years. ${ }^{7}$ One approach is to track how meaning changes over time, as for example in Motta \& Baden (2013), who analyze how "semantic structures" like frames change over time, or Koteyko (2007)'s diachronic approach to meaning in English/Russian loanwords. More generally, these types of studies are interested in tracking changes in language-use, often within a framework called Modern Diachronic Corpus-Assisted Discourse Studies (MD-CADS) (Partington, 2010). Koteyko, Thelwall, \& Nerlich (2010)'s study of "carbon compounds" provides a general framework for diachronic mapping (see also Koteyko, 2010, 2015).

This paper draws together conceptual and methodological characteristics from these lines of scholarship to help conceptualize a framework for assessing rhetorical effectiveness. It contends that the ability to computationally identify semantically differentiated rhetorical expressions, coupled with means of tracking how they replicate across large textual corpora and measuring changes in their prevalence, can be understood as a measure of rhetorical effect.

\section{Methodology for the Test Case}

For testing the effectiveness of rhetorical language specifically, discursive sites like Congressional deliberations can offer textual corpora that are explicitly rhetorical (i.e., structured to be deliberatively persuasive; offering claims and evidence; attuned to audience; created with the purpose of agonistic engagement), instead of generically representative of common language patterns, public opinion, or structural features of a 'text' more broadly defined (as, e.g., in Park et al., 2014).

The daily proceedings of Congress are transcribed in the Congressional Record, which records all announcements and debates of both houses of Congress. Averaging around 272 pages a day, it is, according to the Library of Congress, a

\footnotetext{
${ }^{7}$ See also Kessler \& Graham (2018) for why diachronic approaches to analyzing rhetorical practices are necessary.
} 
"substantially verbatim account of the proceedings of Congress." To retrieve the daily issue of the Congressional Record and build a textual corpus for analysis, a custom script was written ${ }^{8}$ to access the GPO's publications repository and extract the relevant files into a database indexed by date. Each date in the index can contain multiple documents; a document represents a statement or set of related statements made on the floor of House or Senate, as demarcated by the editors of the Congressional Record.

The resultant corpus of Congressional deliberations used for this paper includes Congressional proceedings from 1994 through 2016, encompassing 572,901 documents. To accommodate limitations in available processing power for the analysis, the database was reduced to documents that included mentions of "climate change" or "global warming." The reduced corpus encompassed 5679 documents with a total of 275,208,081 words (excluding punctuation; word count was determined through Python's regular expression engine), and 31678 mentions of "climate change" or "global warming." Table 1 shows the number of documents containing the terms "climate change" or "global warming," number of words in those documents, and total mentions of the key terms, by year, along with descriptive statistics both from the keyword-reduced corpus and the total corpus, including the percentage of documents containing mentions of "climate change" and "global warming" relative to the total number of documents for each year.

Rhetorical analyses generally begin by reading texts with an eye toward semantic uniqueness and differentiation-lexical, syntactic, or semantic structures and expressions that function purposefully, toward a judgment of the specific context in which they occur, in ways they might not in other semantic contexts. To scale this approach---to identify these salient semantic features across the large textual corpus---the text was first segmented into a list of bigrams: a sequence of all two-word units that make up a discourse, such as ["to identify," "identify salient," "salient semantic," ...] in this sentence. ${ }^{9}$ Sorting bigrams that included the term "climate" or "warming" by frequency made it possible to notice interesting patterns; specifically that, among a number of noun-based bigrams that are expected and thus of little interest in any text about climate change (like "global climate" and "climate science") were bigrams that included two verbs: "address(ing)" and "combat(ing)." Indeed, when the words in each bigram across the Congressional Record corpus were tagged by their function as parts-of-speech, the resultant list of bigrams showed that verbs like "addressing" or "observe" appeared over 300 times, while more active verbs like "combating" or "fighting" appeared around 100 times.

\footnotetext{
${ }^{8}$ Links to all code written for this study are listed in Appendix 1

${ }^{9}$ Rationales for sequential over bag-of-words-based approaches to inductively discover semantically interesting features in large textual corpora include Koteyko et al.: "the lexical environment of a search term [... helps provide] a 'feel' of the corpus and a 'map' of key junctions" (2013, p. 77); Nerlich et al.: "[...] the simple and obvious fact that human language is an inescapably sequential phenomenon" (2012, p. 48). See also Grundmann \& Krishnamurthy (2010)'s argument on "the phraseological tendencies of all languages, whereby the choice of one word tends to favor the co-selection of other words, its collocates, within close proximity in a text."
} 


\begin{tabular}{rrrrrrr}
\hline & \multicolumn{3}{c}{ "Climate change" and/or "global warming" only } & & \\
\cline { 2 - 5 } & Documents & Words & Mentions & Avg. mentions/doc. & Total docs & \% of docs/total docs \\
\hline 1994 & 60 & 3599556 & 160 & 2.67 & 23299 & $0.26 \%$ \\
1995 & 57 & 5800335 & 211 & 3.70 & 29046 & $0.20 \%$ \\
1996 & 64 & 7147146 & 181 & 2.83 & 21226 & $0.30 \%$ \\
1997 & 136 & 5396529 & 584 & 4.29 & 23042 & $0.59 \%$ \\
1998 & 152 & 9926538 & 562 & 3.70 & 22844 & $0.67 \%$ \\
1999 & 127 & 7486992 & 487 & 3.83 & 24075 & $0.53 \%$ \\
2000 & 110 & 7189935 & 445 & 4.05 & 23119 & $0.48 \%$ \\
2001 & 195 & 10962738 & 1176 & 6.03 & 23563 & $0.83 \%$ \\
2002 & 120 & 8342691 & 1236 & 10.30 & 21725 & $0.55 \%$ \\
2003 & 195 & 17370003 & 1358 & 6.96 & 25649 & $0.76 \%$ \\
2004 & 110 & 6427539 & 405 & 3.68 & 23012 & $0.48 \%$ \\
2005 & 182 & 11743056 & 1823 & 10.02 & 26538 & $0.69 \%$ \\
2006 & 176 & 8605581 & 705 & 4.01 & 22392 & $0.79 \%$ \\
2007 & 673 & 31843827 & 4066 & 6.04 & 30274 & $2.22 \%$ \\
2008 & 610 & 23276259 & 3043 & 4.99 & 24724 & $2.47 \%$ \\
2009 & 807 & 31886127 & 4109 & 5.09 & 31307 & $2.58 \%$ \\
2010 & 267 & 10732308 & 918 & 3.44 & 25416 & $1.05 \%$ \\
2011 & 217 & 10221573 & 946 & 4.36 & 28544 & $0.76 \%$ \\
2012 & 179 & 9047070 & 862 & 4.82 & 23523 & $0.76 \%$ \\
2013 & 350 & 10361772 & 1727 & 4.93 & 26833 & $1.30 \%$ \\
2014 & 293 & 11366652 & 2348 & 8.01 & 22793 & $1.29 \%$ \\
2015 & 364 & 15679122 & 2776 & 7.63 & 27667 & $1.32 \%$ \\
2016 & 235 & 10794732 & 1550 & 6.60 & 22290 & \\
\hline & & & & & & $1.05 \%$ \\
\hline
\end{tabular}

Table 1: Congressional Record Corpus 
Bigrams that paired "climate" to terms like "addressing", "studying", and "modeling" matched statements like this, by Sen. Feinstein in 2003: "I agree that we should continue to study climate change," or, in 2007, by Sen. Domenici: "One of the most interesting uses of this enormous computer power is modeling climate change." In both examples, members of Congress consider agentic responsibilities to rest in continued examination of climate change phenomena. Bigrams pairing "climate" with combat-related metaphors matched statements like the following, from the Hon. Earl Blumenauer of Oregon: "[...] taxpayer dollars could be better spent renewing and rebuilding our nation's infrastructure and investing in emerging clean resources like wind and solar that will help us combat climate change [...]." Or similarly, over a decade earlier, by Sen. Feinstein: "[...] giving gasoline imports a competitive advantage over cleaner fuel that simply should not exist at a time we are trying to combat climate change." Here, agentic responsibilities are defined instrumentally, not epistemically: the purpose of engaging with climate change is not to learn more about it, but to fight it, to invest immediate resources; these statements foreground a more active, resource-forward role for fighting change.

The prevalence of these lexical framing terms, and analysis of how they were used in actual statements, suggested that "climate change" is frequently referenced in conjunction with what can be called active-agentic or passive-agentic frames. Both are frames that are driven by the possibility of agency, and an ability to act. ${ }^{10}$ They differ on explicit material support: where the active-agentic "combat" frame seeks immediate intervention that demands corresponding material investment, the passive-agentic "address/observe" frame suggests a more measured orientation in which needs for solutions are raised but material support for those solutions is not (yet) made explicit. Active-agentic frames motivate direct action; passive-agentic frames motivate eventual action. In the bigram-based reading of the full corpus, the relative frequency difference hence suggested that Congressional deliberations more frequently frame our agentic capabilities toward climate change in terms of continued evaluation with the goal of eventual action instead of resource-forward intervention.

The bigram-based segmentation of a text corpus provides a high-level overview of the "semantic fields" predominant in a large corpus (Koteyko et al., 2013, p. 77). Once general semantic contexts are inductively identified across a corpus, bigrams (or similar sequence-based approaches, like keyword/frequency lists, collocation, or concordance) offer comparably little for engaging in directed, deductively-driven semantic analysis, however. The following statement from a recent Congressional Record illustrates this difference:

Mr. WHITEHOUSE. Mr. President, I rise today for the 110th time to ask my colleagues to wake up to climate change. Long after today's debate has died down, it will still be looming and threatening. We stand now at the precipice of an environmental catastrophe. The

\footnotetext{
${ }^{10}$ See also Figure 2 and its description for the difference between a fully passive frame and the passive-agentic frame.
} 
burning of fossil fuels has unleashed a flood of carbon pollution that is pushing the climate system planetwide into conditions that are unprecedented in human history. It has already permanently altered the world that we will leave to future generations. If we keep sleepwalking through this and allow the carbon flood to continue, we will leave even bigger changes and risk absolute catastrophe.

Of rhetorical interest here is how the statement frames the agentic affordances of human actors. For a rhetorical critic, this dynamic is straightforward to identify, because the semantic content of words like "wake up," "looming", "unleash", and "sleepwalking" as a bookend to "wake up", all are functionally similar within the context and purpose for which they are used. But on a computational level, sequential analysis of words is not designed to tag and track distinctly rhetorical features like these, that differ lexically but resemble functionally and in practice. Hence, while bigrams are useful for exploratory analysis in this paper, they are limited and imprecise tools for analyzing more semantically complex rhetorical expressions. For one, the fact that semantic meaning carries across syntactically different synonyms - i.e., the fact that phrases like "battle climate change" or "struggle against climate change" would have the same rhetorical function in framing climate change as the "combat" and "fight" frames - cannot readily be captured and quantified by bigrams. And secondly, identifying how these semantically related structures shift dynamically over time requires the ability to identify semantically similar but syntactically different rhetorical expressions in a way that can be indexed on a time axis to allow for diachronic mapping.

A second step of the analysis was built on designing regular expression query syntaxes based on the general insights of the bigram-frequency analysis. Regular expressions offer a query syntax that can capture more complex rhetorical structures by accommodating semantic similarities between words, and a wider syntactic range that can precisely specify the syntactic scope of the rhetorical 'unit' (e.g., sentence, phrase, paragraph, distance between keywords, etc.) of interest. Because the bigram-based semantic overview suggested that the verbs "combat" and "address" were frequently paired with climate change, regular expressions were designed to identify instances within each document where "climate change" was referenced within an average paragraph's range to verbs like "combat" or "assess." The initial list of synonyms for the terms that most frequently appeared along "climate" in the bigram list (e.g., to match "measure" or "evaluate" along with "assess" in the assessment category) were drawn from the Wordnet corpus in Python's NLTK module. Additional synonyms were generated from samples from the Congressional Record corpus that were matched by regular expressions with the initial synonym list. The resultant regular expression syntaxes used in the analysis are listed in Appendix 1. They matched rhetorical expressions like the following, by former Senator Daniel Akaka (D-Hawaii), who in 2001 sought to both create urgency and challenge to zero-sum logic of positioning climate change mitigation opposite economic growth: 
We cannot wait for further scientific proof to materialize [...] An effective program to fight climate change need not involve huge increases in energy prices or draconian rules that choke industries and damage our economic well-being. We need to employ creative approaches and let American ingenuity loose.

Or, as an example of the passive-agentic frame, Chris Coons (D-Delaware) in 2015 advocates action, but framed less urgently:

My thinking is that the entire Federal Government should make responsible, timely, and thoughtful plans to assess and to prepare for prudent mitigation of the future impacts of climate change in our infrastructure. So I am hopeful that this will be among the many amendments that will be taken up, debated, discussed, and passed in the coming hours and days.

The following section shows and discusses the results of tracking the prevalence, development, and relative success, or effectiveness, of these competing agentic frames about climate change across large time spans and large sets of text.

\section{Mapping Effective Agentic Frames in Congres- sional Deliberations on Climate Change}

Running queries with the regular expressions discussed in the preceding section (see Appendix 1) across the Congressional Record corpus identifies 4009 activeagentic frames, and 5322 passive-agentic frames. The relative difference between these numbers is expected, as it matches the relative difference between "combat"based and "address/observe"-based bigrams in the high-level overview of semantic contexts in the corpus. Given the large time frame the corpus spans, these aggregate numbers are of limited interest to rhetorical inquiry, however, as they fail to reflect the dynamic norms (Luhmann's "emergent reality") relevant to the analysis of rhetorical effects. Mapping the emergence of frames over time, on the other hand, demonstrates that in terms of relative frequency, active-agentic frames have made gains on and overtaken passive-agentic frames.

Figure 1, below, shows how over the first few years of the corpus, Congressional deliberators used passive-agentic frames more frequently than active-agentic frames. From 2007 through 2009, the use of both frames spikes; this is to be expected based on the descriptive corpus statistics in Table 1. Of interest, however, is that after the spike, the relative frequency of the passive-agentic frame compared to the active-agentic frame (the active:passive ratio across the corpus is 0.749 ) not only decreases consistently, but that in some years active-agentic frames eclipse passive-agentic ones even in absolute frequency. The prevalence of passive-agentic frames had occasionally decreased earlier, for example in 2006, when the ratio of active-agentic to passive-agentic surpassed the corpus-wide 
frame ratio of 0.749. But only starting in 2010, when aggregate Congressional attention to climate change (as measured by \# of documents in the corpus) began waning, did the active-agentic framing begin to consistently increase in prevalence relative to passive-agentic frames. In the final year on record, 2016, active-agentic frames were almost twice (at a 1.722 ratio) as prevalent as passiveagentic frames. This change in relative frequency, as a measure of emergent rhetorical effectiveness (i.e., of the changing prevalence of a rhetorical expression relative to another), is shown on the bar plot as the ratio of active-agentic to passive-agentic frames above each active-agentic bar.

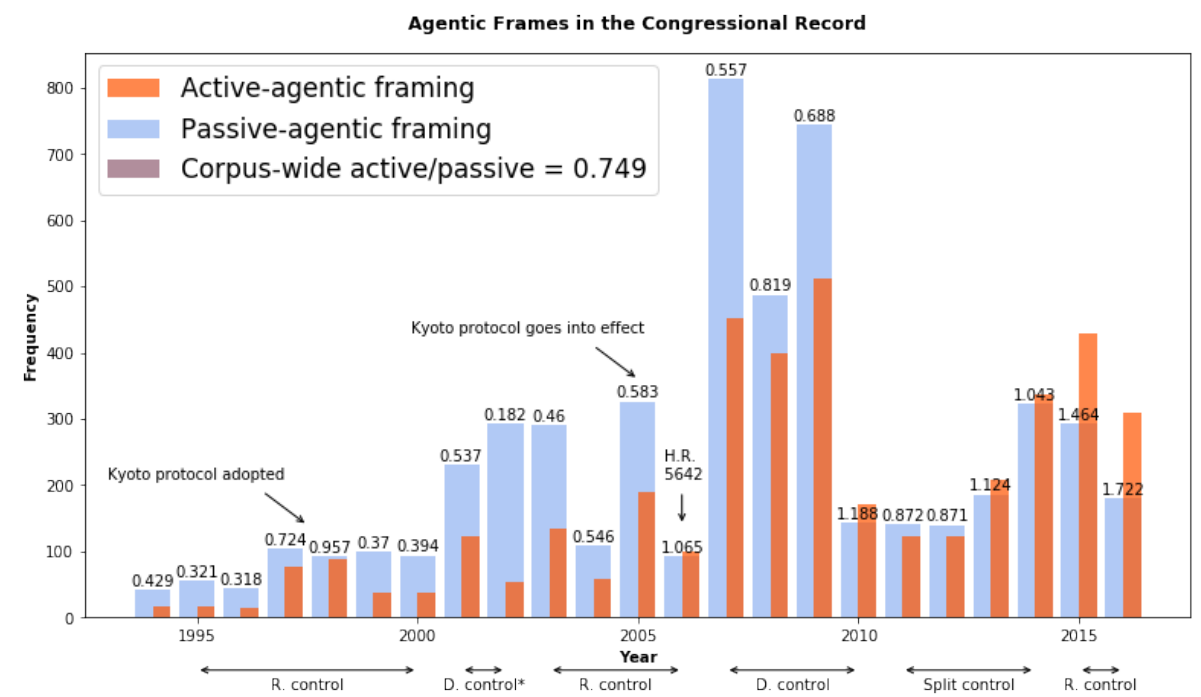

Figure 1: This figure shows the ratios between active-agentic and passive-agentic frames in Congressional discourse, from 1994-2016, along with descriptors like party control of Congress and major climate-related events.

Of potential interest is how such analyses of rhetorical effect have the flexibility to expand to related rhetorical structures, like Burkean frames or pentadic ratios in this instance. Burke argued that situations where "scenic" elements are symbolically foregrounded tend to shift perceptions of agency toward the passive; situations where the acts of agents are foregrounded shift attitudes toward agentic possibility. These moves can be epideictic: the latter carries connotations of not only agency but, with it, praiseworthiness or culpability; the former shifts culpability or praiseworthiness away from the (human) agent (see, e.g., Ling, 1970).

In climate change deliberation, these differences often appear as emphases on change being natural (slow, cyclical, expected) and climate change being anthropogenic (or human-made/caused). Figure 2 shows the results of parsing the text corpus with regular expressions that collocate "climate change" with 
terms like "anthropogenic," "human-caused," or "man-made," and "natural," "cyclical," or "slow," respectively. The temporal changes in pentadic ratios are visibly similar to the temporal shift in frames in figure 1, with agent-centric frames rising consistently in relative frequency in the late 2000s. The only difference - the more frequent prevalence of agentic over scenic ratios in the early years of the corpus - makes sense considering that Figure 1 includes only agentic frames, while the Burkean scenic ratio is more traditionally passive.

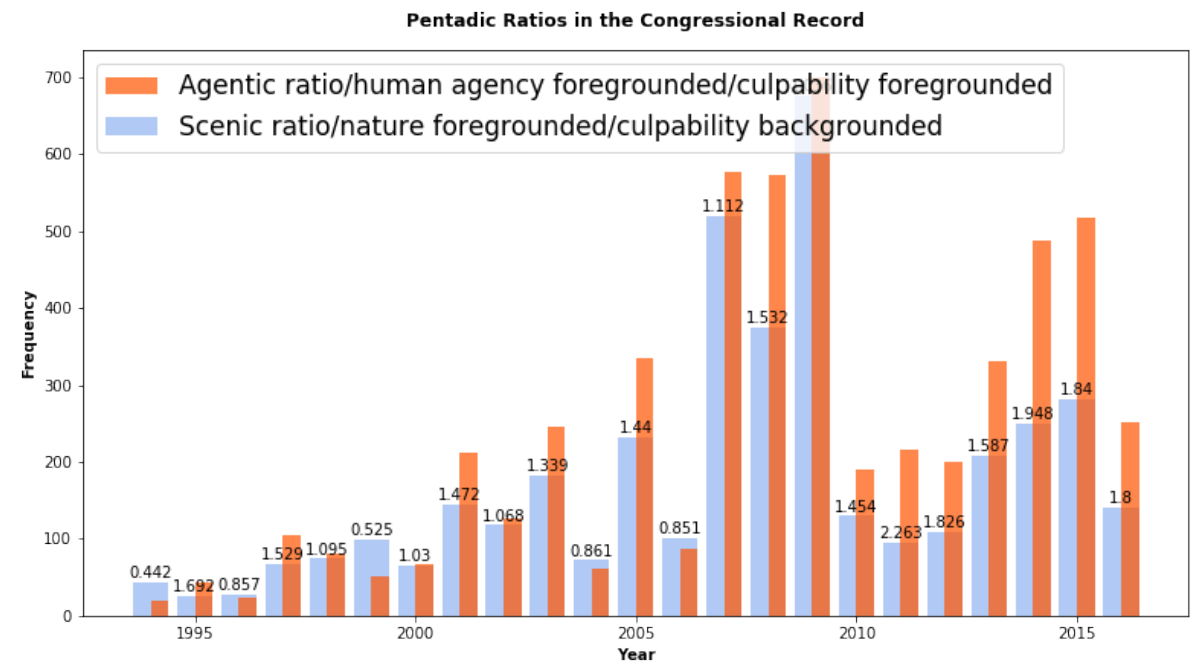

Figure 2: This figure shows the ratios between Burkean agentic and scenic ratios in Congressional discourse, from 1994-2016

The results of the corpus analysis demonstrate that while passive-agentic frames remain most common across the corpus, active-agentic frames have become more prevalent over the last few years. If rhetorical effects are theorized as the changing prevalence of textual imprints over time across an extended body of texts, the results show that it is important to understand rhetorical effectiveness not only as monolithic frequency. The test case demonstrates how the replication of rhetorical expressions manifests in a textual corpus in both absolute frequency and relative frequency across time, and it demonstrates that when the corpus spans a large time frame, relative frequency between multiple rhetorical expressions better conveys an image of rhetorical effectiveness. It is not the passive-agentic frame that should be seen as more effective in this discourse, despite its advantage in absolute frequency across over two decades. Instead, it is the rise of the active-agentic frame relative to the passive-agentic one, over time, that is most compelling for assessing the rhetorical characteristics and their usefulness for communicative practice in this subset of Congressional deliberations. Hence, rhetorical effectiveness can be conceptualized as systemic: within the scope of a rhetorical problem or question (here, how policy discourse orients views about agency and acting toward climate change), effective rhetorical practices 
increase the prevalence of new 'nodes' - or, conversely, maintain the prevalence of existing ones - that make available and accessible (path)ways or resources for communicating. The shifting balance between these frames points to a shift in how the symbolic frames in Congressional deliberations condition attitudes and perspectives on our agency toward climate change, and speak to the rhetorical effectiveness of active-agentic frames relative to passive-agentic ones.

The results of indexing rhetorical effectiveness to changes in prevalence over time carry several implications for the discursive system. First, they demonstrate a pattern of attention to climate change that runs contrary to what one may believe about how party control of Congress correlates with variances in the quantity of deliberations about climate change. Park et al. (2014), for example, argue (on the basis of an older corpus) that party control does not affect the number of hearings on climate change (p. 246); the results of this test case suggest that in recent years, when looking at the effectiveness of rhetorical features in actual language (instead of structural features, such as number of hearings, or broad content codes), party control correlates with attention to climate change. The results show that from 2007-2009, the number of documents relating to climate change increased significantly (see Table 1), encompassing the two years that both chambers of Congress were under Democratic control for the first time since 1995. Through 2014, control of the chambers was split, and attention to climate change dropped by half or more compared to the 2007-2009 levels, despite increased global attention to climate change.

Interestingly, Park et al. (2014) also suggest a qualitative difference: that Democrat-controlled Congresses may help "facilitate proactive legislative efforts on climate-related issues" (p. 253). Because Democrats are seen to be more invested in combating climate change, this is likely a common belief. Yet, the results of this study show that proactive, active-agentic frames in fact increase in effectiveness (as measured by prevalence) in Congresses with split control and hit a distinct tipping point in Republican-controlled Congresses (starting 2015), compared to when Democrats hold both chambers. In fact, while not included in the results because of submission timelines, running the regular expression queries on a version of the Congressional Record corpus database that is up-to-date through 12/31/2017 (and hence both a White House and Congressional majority that are opposed to aggressive environmental regulation) shows a ratio of active-agentic to passive-agentic frames of 2.000 . This ratio is by far the highest of any year in the corpus, with active-agentic frames being more effective than in any previous year.

For technical communication, these results have two implications. One is that for practitioners who want to intervene in climate change deliberations, using active-agentic framing of their message will have a high chance of acceptance or intelligibility within this particular discursive system. Active-agentic frames confer, to follow Luhmann, guarantees of acceptability, "of connection for the next communication that can now either build on an already attained consensus or seek dissent." Studying rhetorical effects within this paradigm can, so, provide 
resources for rhetorical action. But two, following Miller, the results also suggest points of questioning, of discussing how to distinguish good from bad practice. What do they tell us about commonly help presuppositions about the state and process of Congressional deliberations on climate science, and how do such presuppositions affect our orientations toward others as we engage in climate advocacy? Why do internal Congressional deliberations about climate change differ, in their agentic framing, from how many members of Congress frame this debate for their constituents? These are questions about good and bad communicative practice, about motivations, about expectations of reciprocity and more, that raise the stakes of analyzing rhetorical effects for TC scholars from, to again quote Miller, techne to praxis.

It is evident, then, that rhetorical effectiveness ought to be understood as distinct from other means of assessing the success of a semantic feature in a discursive corpus. While structural measures such as number of hearings devoted to a topic, or corresponding syntactical measures like frequency counts of key terms applied to a topic, may drop in frequency, rhetorical engagement oriented toward that topic may in turn increase in effectiveness, possibly because decreased opportunities for frame use create exigencies for renewed agonistic counter-efforts. The formulation of rhetorical effectiveness offered here, whereby effect is understood in a systems-paradigm, indexed to increases or decreases of prevalence of rhetorical expressions over time, and measured in relative frequency against other rhetorical moves, supports these observations: it suggests that rhetorical success lies not in a solitary or monolithic advantage a frame or other rhetorical expression holds in terms of its absolute frequency in a discourse, but that it lies in increasing the prevalence of new communicative resources relative to existing ones. This may be one way of understanding rhetoric within the classical paradigm as phronesis, as a praxis oriented toward and responsive to the needs and good of the community (Miller, 1989).

This view of effect also offers insight into the development of rhetorical norms through stases. Looking at dynamic change over time, the results show that the relationship between passive-agentic and active-agentic frames is relatively stable through 2008 (i.e., remains close to or below the corpus-wide ratio of 0.749; with an exception in 1997-1998, around the time the Kyoto protocol was finalized and adopted, which saw active-agentic frames come close to or surpassing the average ratio; and 2006, the year in which the House held hearings on climate change and introduced the Safe Climate Act of 2006 (H.R. 5642) ${ }^{11}$ ). Following a period of high discursive activity (2007-2009) at the previous static, corpus-wide ratios between the frames came a few years of contraction, where the ratio between the two types of frames came closer to even (hence, active-agentic frames gained in relative prevalence), representing a true point of "frame stasis" over the role of human agency. This was followed by reversal, where active-agentic frames

\footnotetext{
${ }^{11}$ In a writeup of House hearings, Peter Folger (2006), then-Director of Research at the American Geophysical Union, noted that while Republicans saw the hearings as being about education and deepening understanding, Democrats on the committee "expressed their desire to move beyond the science and take action to address climate change."
} 
surpassed passive-agentic ones, accompanied by increased overall frequency of climate change deliberations (see Table 1; Figure 1), and eventually reaching a clear tipping point in 2015. Hence, the results evidence a dynamic pattern of stasis development within a systems-paradigm: external drivers (party control of Congress, high-profile hearings, international agreements, etc.) amplify the use of static norms that have settled over time, calling their propriety or legitimacy or usefulness into question, which leads to clash and eventual resolution (either return to old norms, or as here, reversal to new norms).

\section{Summary and Implications}

The insights and arguments of this study should, at this point, be considered a test case for the usefulness of mapping rhetorical effects, rather than a complete representation of effective rhetorical practices on climate change in Congressional discourse. Whether the pattern of rhetorical stasis is unique to this corpus or an example of a more general model of rhetorical stasis in large discursive systems needs to be shown through further research, for example (but see Graham \& Herndl, 2011, for a theoretical exposition on dynamic stasis development in networks). Similarly, whether the interpretation of the correlations between political processes like party control, opportunities for frame use, and resultant rhetorical manifestations translates to other contexts cannot be addressed by this test case alone. The study's contention, however, is that a conceptualization of rhetorical effect across large textual systems as demonstrated in this case opens possibilities for broader theoretical inquiry into rhetorical discourses, into traditional rhetorical constructions like stasis, and (beyond rhetorical scholarship) into communicative praxis in technical contexts, in ways that are not otherwise available.

To move beyond a test case and develop such possibilities, this paper modeled an approach for assessing rhetorical effects built on extant work on inductive semantic differentiation of a textual corpus' semantic contexts, parsing of unstructured text to identify rhetorical expressions, and diachronic mapping of these rhetorical features. Necessary for pursuing questions about rhetorical effect in and for $\mathrm{TC}$ is to consider the size of the discursive space: to argue that something is rhetorically effective on the grounds of changing prevalence over time requires demonstrating such change over large textual corpora. Hence, a methodological challenge for this paper, and for subsequent scholarship on rhetorical effect, is to scale the lines of research on computational linguistics and rhetoric referenced above to datasets of unstructured text exceeding a few hundred documents and a few million words or phrases.

One aspect of this challenge - how to engage in initial, inductive, exploratory reading of a large textual corpus to identify interesting rhetorical features - was, following Nerlich et al. (2012) and Koteyko et al. (2013), addressed by sequencing the corpus into bigrams and sorting them by keyword, part-of-speech, and 
frequency. Despite the availability of semantic parsing tools (see, e.g., Hart, 2001, for an example), scaling the parsing of complex semantic, linguistic structures to a large corpus could best be accomplished by using regular expressions. The structure of rhetorical elements of language tends to be phrase- or sentence-length units of discourse, which raises semantic complexity and commands a syntax that can both accommodate semantic flexibility (through a range of Boolean operators) and control the syntactic relationship of words and other sentence-units relative to each other within and across sentences and paragraphs. The query syntax used in this paper shows the difficulty of scaling these requirements to large corpora: each frame must, by definition, be able to relate the rhetorical features of the frame (the thing to be framed - climate change - and the vehicle through which it is framed) within the scope of an average paragraph's length, and each frame can consist of many functionally/semantically similar but otherwise different words or expressions. The binary nature of any computational framework imposes constraints that make checking for matches with a scope this wide and across a range of semantically related symbols computing-intensive.

Despite the computational overhead of this test case, inherent in its conceptual and methodological practices to assess effects are theoretical questions and assumptions that have long guided rhetorical scholarship, both on the micro-level (rhetorical components of language are semantically complex in a way that syntactic parts-of-speech and similar sentence-level classifications cannot account for) and on the macro-level (concepts like Farrell's rhetorical culture and its relationship between general norms and specific practices). This suggests two considerations. One is that the design and interpretation of computationallyderived rhetoric practices is, at its core, an inventive process that requires both the critical skill of humanistic criticism (viz., the identification of textual elements that are rhetorically salient to the text ${ }^{12}$ ), and the analytical skill of abstracting semantic textual elements into a computer-readable syntax. The other is that if the goal of computational approaches to rhetorical effect is to preserve the semantic and structural complexity of rhetorical practice, then the more sensitive the computational approach can be to the constant re-configuration of norms, practices, and semantic contexts of a discursive space, the more fitting this kind of model of rhetorical effectiveness becomes for directing scholarly inquiry toward questions of rhetorical effects.

This last point suggests one of three implications of the study, aimed to improve the methodological sensitivity, theoretical strength, and disciplinary value of assessing rhetorical effects as demonstrated here.

The first is that for a computational approach to a theory of rhetorical effect to be useful requires sensitivity to the nuances of rhetorical practices, both semantically (identifying fitting synonyms for central expressions; accounting for negation; etc.) and syntactically (capturing rhetorical moves that extend past

\footnotetext{
${ }^{12}$ See also Hart's (2001) contention that he has found his approach to computerized content analysis - a different method to the one exemplified in this study, but related conceptually - to be "creative" rather than mechanical, and requiring "subtlety" (p. 43).
} 
sentence-levels). Although increase in scope (from single-text to large corpus) will always come at a cost to precision, methodological choices can increase the reliability of computationally parsing rhetorical expressions. For example, bigram-based assessment of a corpus' semantic contexts could be expanded to topic modeling to add reach, topic models may allow for tracking of more complex frames (thematic frames, Burkean frames, etc.), concordance-based views into the corpus to add deeper context, and n-grams larger than two to add wider semantic context to key terms.

The second is that this paper's arguments about rhetorical effects should be considered in the context of existing frameworks for assessing the effectiveness of rhetorical practices. Ceccarelli's On the Frontier of Science (2013), for example, looks to the institutional practices of the NSF and to actual audience responses to demonstrate the effectiveness or lack thereof, respectively, of a particular metaphor. Leff's re-visiting of Lincoln at Cooper Union puts the text in conversation with its social and political context (2001). Foust and O'Shannon Murphy analyze frame success in newspapers (2009). DeVasto's (2016) new materialist framework looks to material practices as evidence of rhetorical work. Harris (2005) argues for reception studies in the rhetoric of science (and, presumably, rhetoric more generally; see also Kelly, Abbott, Harris, et al., 2010). This is not the space for a more exhaustive list; the contention is that a range of distinct perspectives on rhetorical effectiveness exists, and the framework exemplified in this paper could be a complement - another tool-to existing concepts of rhetorical effectiveness.

The third is use-value for communicative practice in technical contexts. This paper argued that the characterization of rhetorical effect and the methodological for mapping effectiveness across large discursive spaces can offer resources to technical communicators by mapping the communicative practices that are "settled" and "can be called on" in a discursive system with reduced risk of rejection, identifying nodes or positions "of connection for the next communication that can now either build on an already attained consensus or seek dissent (Luhmann, 1992). It so doing, this approach shows the development of institutions-as-communicative norms, and offers, to follow Miller (1989), points for distinguishing and questioning what are and what ought to be good practices of communication within our discursive institutions. 


\section{Appendix 1}

Below are the regular expressions used in the analysis. All are designed to match frame synonyms within a set max. distance both before and after mentions of "climate change":

Figure 1: Active-agentic frame:

$\backslash \mathrm{b}$ (climate $\backslash$ schange|global \swarming $) \backslash \mathrm{W}+(?: \backslash \mathrm{w}+\backslash \mathrm{W}+)\{0,150\}$ ?(fight(ing)?|(battle|battling)|must act|combat(ing)?|(struggle|struggling)|(oppose|opposing)|fight(ing)? ’sback|defend(ing?)|press(ing)?|push(ing)?|ce act|combat(ing)?|(struggle|struggling)|(oppose|opposing)|fight(ing)?〈sback|defend(ing?)|press(ing)?|push(ing)?|ce

Figure 1: Passive-agentic frame:

$\backslash \mathrm{b}$ (climate $\backslash$ schange $\mid$ global $\backslash$ swarming $) \backslash \mathrm{W}+(?: \backslash \mathrm{w}+\backslash \mathrm{W}+)\{0,150\} ?(($ examine $\mid$ examining $) \mid$ study(ing)?|assess(ing)?|r

Figure 2: Agentic ratio foregrounded:

$\backslash \mathrm{b}($ climate $\backslash$ schange|global $\backslash$ swarming $) \backslash \mathrm{W}+(?: \backslash \mathrm{w}+\backslash \mathrm{W}+)\{0,150\}$ ? (manmade|anthropogenic|human-caused|cause(d|s)?)|(man-made|anthropogenic|humancaused $\mid$ cause (d)? $) \backslash \mathrm{W}+(?: \backslash \mathrm{w}+\backslash \mathrm{W}+)\{0,150\}$ ? (climate $\backslash$ schange $\mid$ global $\backslash$ swarming $) \backslash \mathrm{b}$

Figure 2: Scenic ratio foregrounded:

$\backslash$ (climate $\backslash$ schange|global $\backslash$ swarming $) \backslash \mathrm{W}+(?: \backslash \mathrm{w}+\backslash \mathrm{W}+)\{0,150\}$ ?(nature|natural|cycle|cyclical|slow)|(nature|natur

Below is the link to the code base used for the analysis, with the following information contained in each file:

[http://<persistent URL from author $>$ ]

'crec_scraper.py' contains the script used to access the GPO's Congressional Record and insert new documents into an SQLite database ("crec.db"). The script can be run manually, or more efficiently through a scheduled, daily cron-job from a virtual server.

'crec_analysis.py' contains the main code for the analysis in this study. It has in-line comments to help navigate its contents; four global variables QUERY1 through QUERY4 contain the regular expressions used for the analysis.

These files can be opened by any text editor to review contents, or downloaded to run. The source code can run on any system with the requisite dependencies installed. 


\section{References}

Black, E. (1970). The second persona. Quarterly Journal of Speech, 56(2), 109-119.

Boykoff, M. T. (2007). Flogging a dead norm? Newspaper coverage of anthropogenic climate change in the United States and United Kingdom from 2003 to 2006. Area, 39(4), 470-481.

Browne, S. H. (2001). Response: Context in critical theory and practice. Western Journal of Communication, 65(3), 330-335.

Cagle, L. E., \& Tillery, D. (2015). Climate change research across disciplines: The value and uses of multidisciplinary research reviews for Technical Communication. Technical Communication Quarterly, 24 (2), 147-163. https://doi.org/10.1080/ 10572252.2015.1001296

Campbell, K. K., \& Jamieson, K. H. (1978). Form and genre in rhetorical criticism: An introduction. In K. K. Campbell \& K. H. Jamieson, (Eds.), Form and genre: Shaping rhetorical action (pp. 9-32). Falls Church, VA: Speech Communication Association.

Ceccarelli, L. (2013). On the frontier of science: An American rhetoric of exploration and exploitation. East Lansing: Michigan State University Press.

David, O., Lakoff, G., \& Stickles, E. (2016). Cascades in metaphor and grammar. Constructions 83 Frames, 8(2), 214-255. https://doi.org/10.1075/cf.8.2.04dav

Derkatch, C. (2018). The self-generating language of wellness and natural health. Rhetoric of Health \& Medicine, 1(1-2), 132-160. https://doi.org/10.5744/rhm.2018.1009

Dodge, E. K. (2016). A deep semantic corpus-based approach to metaphor analysis. Constructions \& Frames, 8(2), 256-294. https://doi.org/10.1075/cf.8. $2.05 \mathrm{dod}$

Entman, R. M. (1991). Framing U.S. coverage of international news: Contrasts in narratives of the KAL and Iran Air incidents. Journal of Communication, 41(4), 6-27. https://doi.org/10.1111/j.1460-2466.1991.tb02328.x

Farrell, T. B. (1993). Norms of rhetorical culture. New Haven: Yale University Press.

Folger, P. (2006). AGU scientists testify at climate change hearings. Eos, 87(36), 367.

Foust, C. R., \& Murphy, W. O. (2009). Revealing and reframing apocalyptic tragedy in global warming discourse. Environmental Communication, 3(2), 151-167. https://doi.org/10.1080/17524030902916624

Gabrilovich, E., \& Markovitch, S. (2007). Computing semantic relatedness using wikipedia-based explicit semantic analysis. In $I J c A I$ (Vol. 7, pp. 1606-1611). 
Gawryjolek, J., Dimarco, C., \& Harris, R. (2009). An annotation tool for automatically detecting rhetorical figures - system demonstration. In Proc. of the IJCAI-09 Workshop on Computational Models of Natural Argument, http://www.cmna. info/CMNA9/Proceedings/CMNA9-Gawryjolek\% 20et\% $20 a l$. $p d f$

Good, J. (2008). The framing of climate change in Canadian, American, and international newspapers: A media propaganda model analysis. Canadian Journal of Communication, 33(2), 233-255.

Graham, S. S., \& Herndl, C. G. (2011). Talking off-label: The role of stasis in transforming the discursive formation of pain science. Rhetoric Society Quarterly, 41(2), 145-167. https://doi.org/10.1080/02773945.2011.553764

Graham, S. S., Kim, S.-Y., DeVasto, D., \& Keith, W. (2015). Statistical genre analysis: Toward big data methodologies in technical communication. Technical Communication Quarterly, 24(1), 70-104. https://doi.org/10.1080/10572252. 2015.975955

Greene, R. W. (1998). Another materialist rhetoric. Critical Studies in Mass Communication, 15(1), 21-40. https://doi.org/10.1080/15295039809367031

Grundmann, R., \& Krishnamurthy, R. (2010). The discourse of climate change: A corpus-based approach. Critical Approaches to Discourse Analysis Across Disciplines, 4(2), 125-146.

Harris, R. A. (2005). Reception studies in the rhetoric of science. Technical Communication Quarterly, 14(3), 249-255. https://doi.org/10.1207/ s15427625tcq1403_2

Hart, R. P. (1984). Systematic analysis of political discourse: The development of diction. Political Communication Yearbook, 1, 97-134.

Hart, R. P. (2001). Redeveloping Diction: Theoretical considerations. In M. D. West (Ed.), Theory, method, and practice in computer content analysis (pp. 43-60). Greenwood Publishing Group.

Hart, R. P., \& Jarvis, S. E. (1997). Political debate forms, styles, and media. American Behavioral Scientist, 40(8), 1095-1122.

Heidt, S. (2012). The presidency as pastiche: Atomization, circulation, and rhetorical instability. Rhetoric \& Public Affairs, 15(4), 623-633.

Herndl, C. G., \& Cutlip, L. L. (2013). "How can we act?" A praxiographical program for the rhetoric of technology, science, and medicine. Poroi, 9(1). https://doi.org/10.13008/2151-2957.1163

Hoffman, D., \& Waisanen, D. (2015). At the digital frontier of Rhetoric Studies: An overview of tools and methods for computer-aided textual analysis. In J. Ridolfo \& W. Hart-Davidson (Eds.), Rhetoric and the digital humanities (pp. 169-183). University of Chicago Press. 
Jisup Hong. (2016). Automatic metaphor detection using constructions and frames. Constructions \& Frames, 8(2), 295-322. https://doi.org/10.1075/cf.8.2. 06hon

Kaufer, D., \& Hariman, R. (2008). Discriminating political styles as genres: A corpus study exploring Hariman's theory of political style. Text $\&$ Talk-An Interdisciplinary Journal of Language, Discourse Communication Studies, 28(4), 475-500.

Kelly, A. R., Abbott, N. A., Harris, R. A., DiMarco, C., \& Cheriton, D. R. (2010). Toward an ontology of rhetorical figures. In Proceedings of the 28th ACM International Conference on Design of Communication (pp. 123-130). New York, NY: ACM. https://doi.org/10.1145/1878450.1878471

Kessler, M. M., \& Graham, S. S. (2018). Terminal node problems: ANT 2.0 and prescription drug labels. Technical Communication Quarterly. Advance online publication. https://doi.org/10.1080/10572252.2018.1425482

Keränen, L. (2010). How does a pathogen become a terrorist? The collective transformation of risk into bio(in)security. In J. Leach \& D. Dysart-Gale (Eds.), Rhetorical questions of health and medicine (pp. 77-96). Lanham, MD: Lexington Books.

Kiewe, A., \& Houck, D. W. (Eds.). (2015). The effects of rhetoric and the rhetoric of effects: Past, present, future. Columbia, South Carolina: The University of South Carolina Press.

Koteyko, N. (2007). A diachronic approach to meaning: English loanwords in Russian opposition discourse. Corpora, 2(1), 65-95.

Koteyko, N. (2010). Mining the internet for linguistic and social data: An analysis of "carbon compounds" in Web feeds. Discourse 83 Society, 21(6), 655-674. https://doi.org/10.1177/0957926510381220

Koteyko, N. (2015). Corpus-Assisted analysis of internet-based discourses: From patterns to rhetoric. In J. Ridolfo \& W. Hart-Davidson (Eds.), Rhetoric and the digital humanities (pp. 184-198). University of Chicago Press.

Koteyko, N., Jaspal, R., \& Nerlich, B. (2013). Climate change and "climategate" in online reader comments: A mixed methods study. The Geographical Journal, 179(1), 74-86. https://doi.org/10.1111/j.1475-4959.2012.00479.x

Koteyko, N., Thelwall, M., \& Nerlich, B. (2010). From carbon markets to carbon morality: Creative compounds as framing devices in online discourses on climate change mitigation. Science Communication, 32(1), 25-54. https: //doi.org/10.1177/1075547009340421

Leff, M. (2001). Lincoln at Cooper Union: Neo-classical criticism revisited. Western Journal of Communication, 65(3), 232-248.

Ling, D. A. (1970). A pentadic analysis of Senator Edward Kennedy's address to the people of Massachusetts, July 25, 1969. Central States Speech Journal, 
21, 81-86.

Luhmann, N. (1992). What is communication? Communication Theory, 2(3), 251-259. https://doi.org/10.1111/j.1468-2885.1992.tb00042.x

Mann, W. C., \& Thompson, S. A. (1988). Rhetorical structure theory: Toward a functional theory of text organization. Text-Interdisciplinary Journal for the Study of Discourse, 8(3), 243-281.

Miller, C. R. (1989). What's practical about technical writing. Technical Writing: Theory and Practice, 14-24.

Motta, G., \& Baden, C. (2013). Evolutionary factor analysis of the dynamics of frames: Introducing a method for analyzing high-dimensional semantic data with time-changing structure. Communication Methods 83 Measures, 7(1), 48-82. https://doi.org/10.1080/19312458.2012.760730

Nerlich, B., Forsyth, R., \& Clarke, D. (2012). Climate in the news: How differences in mMedia discourse between the US and UK reflect national priorities. Environmental Communication, 6(1), 44-63. https://doi.org/10.1080/17524032. 2011.644633

Nerlich, B., \& Koteyko, N. (2009). Carbon reduction activism in the UK: Lexical creativity and lexical framing in the context of climate change. Environmental Communication, 3(2), 206-223.

Park, H. S., Liu, X., \& Vedlitz, A. (2014). Analyzing climate change debates in the U.S. Congress: Party control and mobilizing networks. Risk, Hazards $\mathbb{E}$ Crisis in Public Policy, 5(3), 239-258. https://doi.org/10.1002/rhc3.12062

Parrish, W. M. (1954). The study of speeches. In W. M. Parrish \& M. Hochmuth Nichols (Eds.), American Speeches. NY: Longmans, Green \& Co.

Partington, A. (2010). Modern diachronic corpus-assisted discourse studies (MD-CADS) on UK newspapers: An overview of the project. Corpora, 5(2), 83-108. https://doi.org/10.3366/cor.2010.0101

Rand, E. J. (2008). An inflammatory fag and a queer form: Larry Kramer, polemics, and rhetorical agency. Quarterly Journal of Speech, 94(3), 297-319. https://doi.org/10.1080/00335630802210377

Ridolfo, J., \& Hart-Davidson, W. (2015). Rhetoric and the digital humanities. University of Chicago Press.

Schäfer, M. S., \& Schlichting, I. (2014). Media representations of climate change: A meta-analysis of the research field. Environmental Communication, 8(2), 142-160. https://doi.org/10.1080/17524032.2014.914050

Slovic, P. (1986). Informing and educating the public about risk. Risk Analysis, 6(4), 403-415. https://doi.org/10.1111/j.1539-6924.1986.tb00953.x

Spoel, P., Goforth, D., Cheu, H., \& Pearson, D. (2008). Public communication of climate change science: Engaging citizens through apocalyptic 
narrative explanation. Technical Communication Quarterly, 18(1), 49-81. https://doi.org/10.1080/10572250802437382

Vink, M. J., Boezeman, D., Dewulf, A., \& Termeer, C. J. A. M. (2013). Changing climate, changing frames: Dutch water policy frame developments in the context of a rise and fall of attention to climate change. Environmental Science 83 Policy, 30, 90-101. https://doi.org/10.1016/j.envsci.2012.10.010

Walsh, L. (2015). The visual rhetoric of climate change. Wiley Interdisciplinary Reviews: Climate Change, 6(4), 361-368. https://doi.org/10.1002/wcc.342

Weber Russell, S. (2008). Abstraction as a basis for the computational interpretation of creative cross-modal metaphor. International Journal of Speech Technology, 11(3/4), 125-134. https://doi.org/10.1007/s10772-009-9042-8

Wichelns, H. A. (1925). The literary criticism of oratory. In A. M. Drummond (Ed.), Studies in Rhetoric and Public Speaking in Honor of James Albert Winans. NY: The Century Co.

Wrage, E. J. (1947). Public address: A study in social and intellectual history. Quarterly Journal of Speech, 33(4), 451-457. https://doi.org/10.1080/ 00335634709381332 